Article

\title{
Outdoor Thermal Comfort in a Transitional Space of Canopy in Schools in the UK
}

\author{
Choul Woong Kwon ${ }^{1, *}$ and Kang Jun Lee ${ }^{2}$ \\ 1 Department of Architecture, Sejong University, Seoul 05006, Korea \\ 2 School of Architecture, Hanyang University, Gyeonggi-do 15588, Korea; leekangjun@gmail.com \\ * Correspondence: hottrinity@gmail.com; Tel.: +44-07400-388-687
}

Received: 29 August 2017; Accepted: 24 September 2017; Published: 28 September 2017

\begin{abstract}
There has been a significant increase in opportunities to improve school environments in the UK. There has, however, been little study on the design of sheltered transitional spaces, despite growing architectural demand for this, examples of which can be easily found in most primary schools in the UK. Computer simulations (Rayman, Ecotect and Winair4) were performed to identify the influence of different parameters: that of having a canopy; the effect of the transmissivity of the canopy material (three transparencies $0 \%, 50 \%$ and $90 \%$ were considered); orientation (four orientations-north, east, south and west-were considered); and location (three cities: London, Manchester and Glasgow). The combined effects of canopy transparency and orientation were shown to be critical design considerations in affecting comfort conditions in outdoor spaces. It was found that outdoor comfort conditions in the transitional space can be enhanced by $41.5 \%$ in August by choosing a canopy of $0 \%$ transparency, compared with a canopy of $90 \%$ transparency in London. The fixed canopy with a higher transparency helped to increase outdoor thermal comfort in Glasgow, while one with a lower transparency showed better performance during summer in London. This research will help design environmentally sophisticated transitional spaces in schools.
\end{abstract}

Keywords: thermal comfort; outdoors; canopy; transitional space; school; UK

\section{Introduction}

\subsection{Background}

Interest in improving not only school buildings, but also school grounds, has recently grown considerably due to the important role played by school grounds within the school curriculum. Approximately $60 \%$ of the sum total of all school estates is land rather than buildings, but often the school grounds are developed without fully considering their potential [1]. Moreover, around $30 \%$ of a child's time in school is spent in the outdoor spaces before and after lessons and during breaks [2]. Several researchers have highlighted that outdoor learning experiences are more effective in developing cognitive skills than classroom-based learning [3,4].

As the school curriculum poses challenges to everyone concerned with teaching, particularly with regard to the National Curriculum, the role of outdoor space as an extension of the indoor classroom and as a framework for future expansion is becoming more important [5].

Transitional spaces, one of the popular typologies of sheltered outdoor spaces, are formed by building elements such as an extended roof, awning, canopy, wall or tree covering or enclosing adjacent areas of the school buildings. These architectural elements play a vital role in manipulating the environmental performance of the sheltered transitional spaces, such as improving outdoor thermal comfort and alleviating adjacent indoor energy demand. Blocking solar radiation, presumably, can increase thermal satisfaction in summer as is commonly experienced outdoors. The high speed of cold air flow in winter can also cause thermal problems, which tend to dissuade people from staying outdoors for longer. 
Sustainable schools could be expected to provide healthier and more productive environments because the factors that contribute to a sustainable building (daylight, fresh air, materials with low pollutants, etc.) correlate strongly with factors known to contribute to health and wellbeing $[6,7]$. Also, some researchers have shown the advantages of using the transitional spaces attached to a building in order to improve energy consumption [8-10]. However, these studies were only focused on the indoor environment and did not include the sheltered transitional space. This approach, in which a study focuses on either indoor or outdoor space alone, is not appropriate for the case of school buildings where outdoor spaces (in particular transitional spaces) are as important as an indoor classroom in schools. There is growing interest in the use of outdoor space, especially in nursery and primary schools. This has led architects and engineers to explore the potential of transitional space and attached outdoor space, through the use of architectural elements to help improve the school environment in both its indoor and outdoor spaces, while providing students with appropriate pedagogical places where they can experience and interact with nature. Therefore, the study of transitional spaces needs to be approached with the environmental considerations of outdoor spaces in mind, as designing and building a transitional space with the intention of maximising outdoor comfort does not always turn out for the better, with respect to the indoor environment and vice versa. Outdoor spaces are an important part of the school environment, providing students with open spaces within which they can run around, meet others and enjoy the natural world. There are no building regulations for outdoor classrooms, however, recommendations for their necessity and design tips can be found in the publications by DfES (Department for Education and Skills) [1,2], which give pedagogical reasons for having such spaces and suggest how the space might be manipulated. Therefore, this study is to help understand that the transitional outdoor space can affect environmental conditions in ways that can enhance both the outdoor thermal comfort of occupants and their appreciation of the space, which helps designers and stakeholders to rethink the value of transitional space. This research can be applicable for the outdoor comfort in urban structures with a modification of environmental factors. Numerical studies were adopted according to different environmental parameters, and computer software packages were used for the numerical simulations.

\subsection{Related Research}

Some studies show how microclimate can be improved through urban structures. Urban structures are composed of a street, canyon, square, green area, etc., most of which can also be applied to the school context from a microclimate point of view [11,12]. With regards to the urban microclimate, Oke (1987) categorised different types of urban structures and analysed each urban space's environmental functions [13]. Outdoor thermal comfort requires different approaches from indoor thermal comfort. Huang et al. [14] investigated behavioural responses to thermal environments differing by gender, age, types of activities and whether open space should feature thermal environments favourable to intended activities and users for better thermal conditions. A popular thermal index, the Predicted Mean Vote (PMV) model [15] has a predicted thermal neutrality at $24.1^{\circ} \mathrm{C}$. In reality, however, Huang et al. observed a value of $27^{\circ} \mathrm{C}$ for these outdoor spaces. From their results, they concluded that thermal sensation outdoors is perceived differently from that indoors and even postulated that indoor thermal comfort standards are not applicable to outdoor settings. Research conducted by Hoppe in 2002 shows that thermal sensation outdoors is perceived differently from thermal sensation indoors, and that indoor thermal comfort standards are not applicable to outdoor settings [16]. Diverse research has also been conducted using thermal comfort index specified for the outdoor in urban studies. Improvement of an urban microclimate may involve the use of more appropriate materials, increased use of green areas, use of cool sinks for heat dissipation, an appropriate layout of urban canopies, etc. These ideas can be applied to specific buildings that require maximum use of outdoor space, such as schools, by enhancing microclimate conditions [9,17]. Modifications of the urban structure and building elements can create thermally comfortable outdoor spaces, which can also be applied to the school environment [18]. A similar study of the urban environment by Steemers et al. (2004) shows the 
significance of architectural and thermal diversity in urban life. Architectural diversity is obtained by the variety of spatial characteristics identified in urban spaces, such as geometry, orientation, the urban structure and materials. With spatial diversity also comes thermal diversity, defined as the variety of microclimate conditions with regards to temperature and air movement in the intra-thermal and inter-thermal environments $[19,20]$.

\subsection{Environmental Factors}

One of the dominant parameters in the degree of comfort of both outdoor and indoor spaces is solar radiation. This is affected by the surroundings, i.e., whether they are open or closed places. In winter, direct solar radiation is considered to be an outdoor resource in the temperature climate zone, whereas glare, either direct or reflected, can be disturbing. Once the incoming solar radiation hits the earth's surface, it is reflected by the quantity of the albedo. This controls the short-wave radiation absorption and affects the long-wave radiation emitted from the ground, and therefore the microclimate of the adjacent air [21]. In general, the amount of light absorbed is inversely proportional to the surface reflectance; higher reflectance means less solar absorption. In a study of urban thermal comfort, Steemers et al. (1999) determined that in narrow streets, shading from the sun provided at ground level by surrounding buildings is more important in improving thermal comfort conditions at the bottom of such streets than the increase in absorbed radiation [22]. The amount of solar radiation falling on any given surface (wall, floor, etc.) changes constantly as a result of the sun changing position in the sky.

Air flow is also one of the crucial factors influencing thermal comfort in outdoor spaces. It is difficult to foresee and control air flow due to global, regional and local factors. It is therefore important to understand that there can be significant differences in the wind environment between one part of a city and another, from the macro scale to the micro scale. From investigating the effects of wind speeds on people, effects of building elevation on modification of the mean flow pattern are analysed, and a method of combining simulated wind and measured thermal parameters to predict outdoor thermal comfort is demonstrated [23].

Oke (1987) investigated the mechanisms of wind approaching a building. The wind field in the urban environment is affected by the roughness of terrain, which causes a decrease in the wind speed at low levels. However, the vertical gradient for the mean wind speed is flatter, with the city acting as a barrier to the air flow, which is pushed upwards [24].

Mitigation measures can be taken to avoid discomfort imposed on people by excess wind, by displacing the problem to a higher level above the pedestrians' range. Shelter from the wind can also be provided by grouped trees, which can reduce wind speeds by up to $20 \%$ of the field speed [25]. An important point to keep in mind is the thermal effect of wind, which varies according to the climate. As the complexity of the airflow in the pedestrian zones in urban areas is very high, even small changes in the layout of the space or neighbourhood can dramatically change the wind pattern in the space. The personal perception of wind speed associated with air flow was researched by Szokolay et al. (1997) [26]. Thermal comfort in relation to the airflow effect does, however, vary according to the climate [27]. Winds may be a burden in the cold or even temperature climates in the winter, but in hot or humid conditions light breezes are pleasant, as wind assists in the cooling of the human body by evaporation. For example, in hot-humid regions during periods of overheating, a higher wind velocity can mitigate the physiological heat stress caused by the high temperature. Furthermore, the tendency of the urban temperature to be above the regional level (the heat island) diminishes as the urban wind speed increases. Setting up a windbreak to avoid cold winds in cooler periods can aggravate summer thermal discomfort with no cooling effect by the wind, unless modifications are made during the warmer period. Thus, it is desirable when designing a windbreak to allow flexibility in the design to meet different seasonal needs [28].

The mean radiant temperature (MRT) is the most important parameter governing the human energy balance, especially on hot sunny days. MRT also has the strongest influence on thermos-physiological 
comfort indices, such as PET (Physiological Equivalent Temperature) or PMV (Predicted Mean Vote), which are derived from heat exchange models. The mean radiant temperature is simply the area-weighted mean temperature of all the objects surrounding the body and plays an important role in influencing thermal perception [29]. The mean radiant temperature is the interactive value of the wind speed, air temperature and radiation of the surroundings. This value uses the most interdependent and combined thermal elements to evaluate the thermal condition of a place. Thus, it can be used as the main environmental factor by which to calculate thermal comfort [30]. Technically, MRT is defined as "the uniform temperature of a surrounding surface giving off blackbody radiation (emissivity $e=1$ ) which results in the same radiation energy gain on a human body as the prevailing radiation fluxes which are usually very varied under open space conditions" [31]. Matzarakis et al. present a formula for the calculation of mean radiant temperature [32]. For this formula to be applied, the relevant properties and dimensions of the radiating surfaces and the sky view factor, as well as the posture of the human body (e.g., seated or standing), must be known. Szokolay and Auliciems [26] explain that it is not possible to measure MRT directly but only through the use of a black globe thermometer, which reacts to radiant input and air temperature. A black painted table tennis ball is frequently used to measure globe temperature. When wind speed $(v \mathrm{~m} / \mathrm{s})$ is zero, $M R T=G T$ as seen by the simplified Equation (1) below, but the adjustment is necessary for wind speed.

$$
M R T=G T \times(1+2.35 \sqrt{v})-2.35 \times D B T \sqrt{v}
$$

To introduce outdoor thermal comfort indices, it is necessary to understand the basic differences between indoor and outdoor spaces. While the indoor environment tends to be relatively steady and controllable, the outdoor environment is defined by daily and seasonal variations of more uncontrollable microclimate parameters (humidity, air temperature, surface temperatures, wind and radiation), which affect the energy budget [16].

The conventional heat balance equation that describes the energy flows between a body and the surrounding is:

$$
M+W+R+C+E D+E r e+E S w+S=0
$$

where

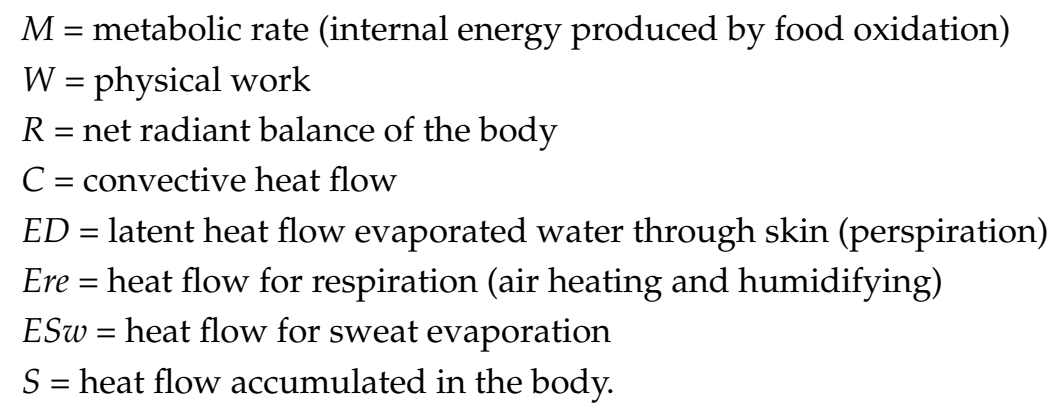

The individual heat flows of Equation (2) are influenced directly by the following climatic parameters:

Air temperature $C, E R e$

Air humidity ED, ESw Ere

Air velocity $C, E s w$

Mean radiant temperature $R$.

The human body does not have sensors to measure each climatic parameter and therefore can only render information from temperatures of the skin and the blood flow passing through the hypothalamus. However, these temperatures are directly influenced by the integrated effect of all the above climatic parameters, which interact with and affect each other. Therefore, in a sunny winter environment with little wind, the mean radiant temperature is just as important as the air temperature, 
and its significance increases in the summer [33]. In Mediterranean countries, $M R T$ easily reaches $60-70{ }^{\circ} \mathrm{C}$ with air temperatures of about $30-35^{\circ} \mathrm{C}$. In windy environments, air temperature becomes more important than radiant temperature because convective heat exchange dominates [34]. Computer simulations are adopted to show the roles played by environmental factors that influence outdoor comfort by building elements design options through parametric design studies.

\section{Methodology}

This study explores the environmental performance of fixed types of canopies, which are attached to school buildings and extend from the building boundary. The type of canopy most frequently found takes the form of an overhang, one side of which is attached to a wall and acts as a mono-pitched roof. Once this canopy is installed, it is not possible to change either the form or the angle at which it is attached. Hence, it is defined as a fixed canopy. Environmental factors (e.g., solar radiation, wind speed, etc.) play an important role in influencing the outdoor thermal comfort in an unheated sheltered semi-outdoor space. Therefore, obtaining values for the environmental parameters on the site to be examined by simulation is a prerequisite for calculating outdoor thermal comfort. In order to calculate PET comfort, different software packages were combined. As there is currently no single software package available to calculate PET comfort using a three-dimensional model (with different transparencies) that takes into consideration the building's materials, it was necessary to use other software packages to generate the required data to be entered into Rayman v1.2 for the calculation of outdoor thermal comfort $[30,35]$.

Before simulating outdoor thermal comfort using Rayman 1.2, preliminary calculations of solar radiation on an hourly basis and wind speed were necessary. Following that, the combined effect of both environmental factors on outdoor thermal comfort was explored, allowing the maximum possible thermal comfort under the combined effects to be determined, as illustrated in Figure 1.

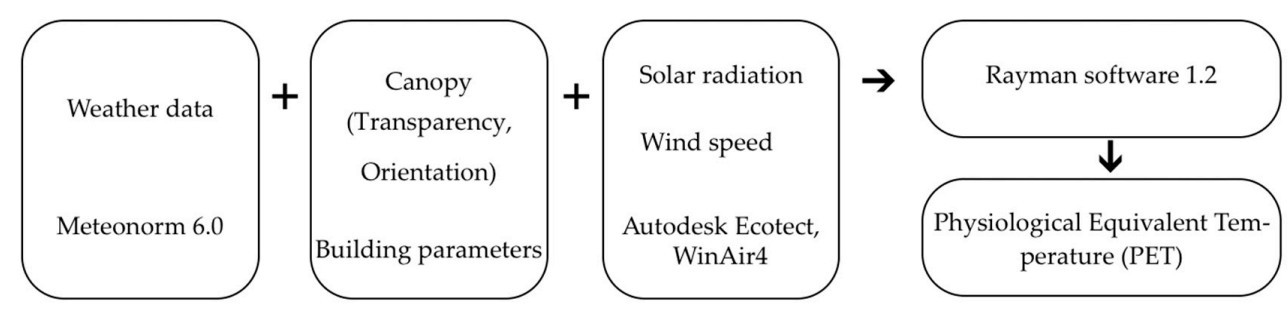

Figure 1. Diagram showing the process of calculating the PET index.

Simplifying the model is a way of reducing the calculation time; it is impossible to model the whole built environment as the physical conditions vary from place to place. It is important to use a simplified model that focuses on the main building elements and to observe how variations in environmental factors alter the environmental performance of the space. For this purpose, software packages for environmental simulation were used to review the impact of each environmental factor. Rayman v1.2 [32] was selected for the calculation of outdoor thermal comfort using the thermal comfort index, Physiological Equivalent Temperature (PET).

It was necessary to analyse UK climates in different places so that it is possible to identify how the use of transitional space in schools can be adapted to consider the local climate. Three large UK cities (London, Manchester and Glasgow) were chosen to represent each climate zone in the UK (north, middle and south climate zones) in order to check how differences in the physical conditions chosen for examination would affect the outdoor thermal index: PET. The UK climate is categorised as temperate maritime, in that there is relatively little seasonal variation in temperature between summer and winter. Though it is difficult to predict the weather due to its changeability, the UK climate is affected by the Atlantic Ocean, which reduces the variation of temperature over the whole year.

The model was based on a design characterised by preliminary research into the common-practice design of classrooms [36]. The size of the classroom under test was 63 square metres $(9 \mathrm{~m} \times 7 \mathrm{~m})$ with 
three classrooms in a row, with a height of $2.9 \mathrm{~m}$. A sheltered semi-outdoor space (represented by a light-green colour in Figure 2) consisting of a $5 \mathrm{~m}$ canopy, the general size of an outdoor classroom, was explored to determine the outdoor thermal comfort. The simulated model was assumed to be built with high-performance building materials according to building regulations (Table 1). The materials in the transitional space were allocated as bricks for wall, timber floor for ground and glass with three different transparencies for the canopy in the computer simulations.

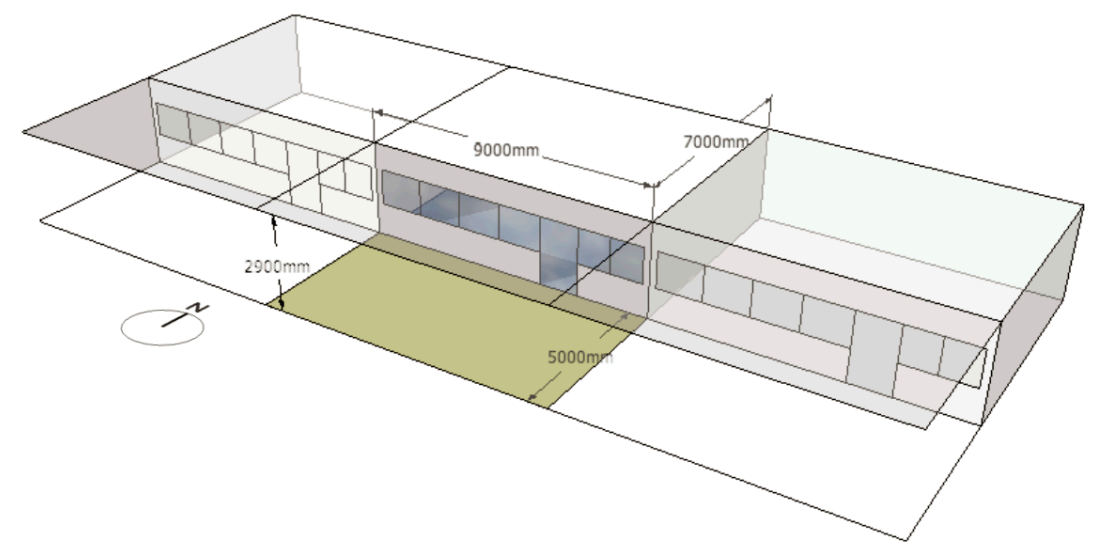

Figure 2. Base computerized model of a classroom.

Table 1. Input data for classrooms.

\begin{tabular}{cccc}
\hline Design Variables & Classroom Built Recently & Design Variables & Classroom Built Recently \\
\hline Orientation & $\mathrm{S}, \mathrm{N}, \mathrm{E}, \mathrm{W}$ & Window $U$-value & $U=2.974 \mathrm{~W} / \mathrm{m}^{2} \mathrm{~K}$ \\
\hline Wall insulation & $U=0.25 \mathrm{~W} / \mathrm{m}^{2} \mathrm{~K}$ & Room dimensions & $9 \mathrm{~m}(\mathrm{w}) \times 7 \mathrm{~m}(\mathrm{~d}) \times 2.9 \mathrm{~m}(\mathrm{~h})$ \\
\hline Roof & $U=0.35 \mathrm{~W} / \mathrm{m}^{2} \mathrm{~K}$ & Canopy dimensions & $9 \mathrm{~m}(\mathrm{w}) \times 5 \mathrm{~m}(\mathrm{~d})$ \\
\hline Infiltration & $0.5 \mathrm{ACH}$ & Reflectance & $\begin{array}{c}\text { Glass material with } 0 \%, 50 \%, \\
90 \% \text { transparency }\end{array}$ \\
\hline $\begin{array}{c}\text { Ventilation } \\
\text { Glazing ratio }\end{array}$ & $\begin{array}{c}\text { Natural ventilation via } \\
\text { openable window } 40 \%\end{array}$ & $\begin{array}{c}\text { Material of the } \\
\text { transitional space }\end{array}$ & $\begin{array}{c}\text { Ground } 0.2 \text { Canopy } 0.5 \\
\text { Brick }\end{array}$ \\
\hline
\end{tabular}

The classroom located in the middle of the row of three was selected for the environmental simulation as it more clearly represents environmental performance affected by orientation and wind speed, in comparison to classrooms located at the corner or end. The meteorological data applied in this study came from Meteonorm 6.0, which includes weather data measured at Heathrow airport, London. Hourly data for the 10-year period of 1996-2005 was used for the detailed simulation.

The size of a semi-outdoor space can vary according to the needs of the school. As an extended classroom or supplementary shared teaching area, for example, for use on a rainy day, the space needs to be large enough to hold all students from the classrooms that share the semi-outdoor space. As there is no specific area schedule for external classrooms, it was necessary to refer to the recommendations for other areas suggested by DfES [37], which shows recommended learning resource areas for any primary school. DfES suggests that the formula used for calculating such areas is $4+1.5 \mathrm{G}$ ( $\mathrm{G}=$ number of pupils), so the attached area for external education can be calculated and applied to the simulation as having an area of $46 \mathrm{~m}^{2}$ based on the normal number of pupils in a small classroom of 28 people in Table 2.

The Ecotect software is best known as a three-dimensional tool with an intelligible interface that is useful for both architects and engineers at the design stage of projects. The role of solar radiation is significant to human thermal perception. Therefore, it was essential to calculate the precise amount of radiation falling on the site under investigation. Autodesk Ecotect was used to compute the incident solar radiation on the specific area. 
Simulations of the south-facing sheltered semi-outdoor space next to the classroom were made with different transparency rates of canopy: $0 \%, 50 \%$ and $90 \%$. A $0 \%$ transparency canopy refers to canopies made from opaque materials that do not allow any light to pass through. The $50 \%$ and $90 \%$ transparencies of canopy permit light to pass through with solar heat gain coefficients of 0.5 and 0.9 respectively.

Table 2. Normal school schedule in England.

\begin{tabular}{|c|c|c|c|}
\hline \multirow{3}{*}{$\begin{array}{l}\text { Total Time } \\
\text { of School } \\
\text { Occupation }\end{array}$} & $\begin{array}{c}6 \text { weeks }=\text { Summer holidays } \\
2 \text { weeks }=\text { Christmas holidays } \\
2 \text { weeks = Easter holidays }\end{array}$ & Occupancy & $\begin{array}{c}30 \text { people } \\
\text { (2 teachers }+28 \text { pupils })\end{array}$ \\
\hline & $\begin{array}{c}1 \text { week } \times 3 \text { times }=\text { Half term } \\
52 \text { weeks }-13 \text { weeks }=39 \text { weeks }\end{array}$ & School terms & $\begin{array}{l}\text { - Spring term: January-March } \\
\text { - Summer term: Mid April-mid July } \\
\text { - Autumn term: September-mid December }\end{array}$ \\
\hline & $\begin{array}{c}(\text { year })-(\text { holidays })=(\text { school days }) \\
195 \text { days } \times 7 h=1365 h\end{array}$ & School hours & 09:00-16:00 \\
\hline
\end{tabular}

The canopy used for the simulation is composed of glass painted black, which can be adjusted to give visible transmittance $(0,0.5,0.9)$ and solar heat gain $(0.1,0.5,0.9)$. In particular, the $0 \%$ transparency (opaque) canopy used to provide theoretical data in this study can be considered as equivalent to other opaque canopies (e.g., timber frame or concrete cantilever). The average hourly solar radiation falling on the experimental grid in Figure 3 was calculated by Autodesk Ecotect [38] from thousands of readings with the help of script functions.

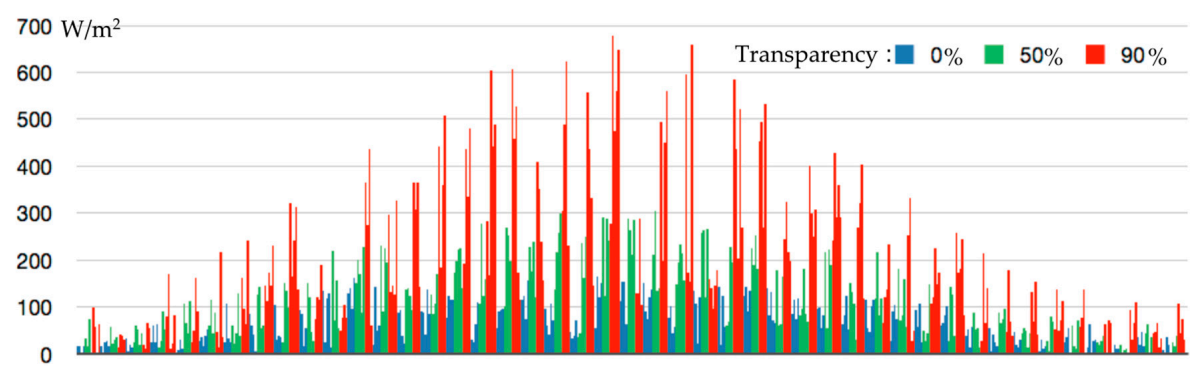

Figure 3. Hourly incident solar radiation (09:00-16:00) throughout the year using different transparencies of canopy (London).

As the contribution of wind speed to thermal comfort is significant, it was an important part of the process to determine the wind speed over a particular area throughout the year. WinAir4 was used for the CFD (Computational Fluid Dynamics) simulation, to transfer the simulated data of the three-dimensional model to Autodesk Ecotect to discern the wind speed. As many researchers have shown from their investigations into the mechanisms by which wind approaches a building [13], wind speed is affected by the terrain roughness, which leads to a decrease in wind speed at low levels in either urban or suburban areas. This varies according to the conditions of the local area. Local wind data is therefore vital when assessing the wind environment in an open space. The mean wind velocity and the direction of the wind during the time the space is occupied are the most important factors to consider. If space is occupied for the whole year, weather data in London should be obtained for all seasons and each month. Wind data can be obtained from the closest meteorological station or from a weather data pack (e.g., Meteonorm 6.0) in which wind speed is usually measured at the height of $10 \mathrm{~m}$ above ground level. The wind data can be modified in a graphical overview of the local wind velocities and directions for a specific site, based on measurements over a period.

Wind speed in the canopy area was calculated for different designs of the sheltered semi-outdoor space. Wind speed varies in relation to site conditions such as the height of the building, its layout and the presence of adjacent trees, all of which influence the wind speed in some way. Calculating the 
hourly wind speed was essential, and a crucial environmental factor in simulating the PET thermal comfort index, as the simulation uses hourly-based weather data to make detailed predictions.

To modify the wind speed, the formula of wind speed estimation in Equation (3), suggested by Spagnolo and de Dear, [39] was adopted and wind speed for each location was derived.

$$
\begin{gathered}
\frac{V_{z e x}}{V_{z 10}}=\left(\frac{Z_{e x}}{Z_{10}}\right)^{\alpha} \\
\alpha=\frac{\log \left(\frac{V_{z e x}}{V_{z 10}}\right)}{\log \left(\frac{Z_{e x}}{Z_{10}}\right)}
\end{gathered}
$$

where

$V_{z e x}$ : the mean wind speed at height $Z(\mathrm{~m} / \mathrm{s})$;

$V_{z 10}$ : the mean wind speed at reference height $Z_{10}(\mathrm{~m} / \mathrm{s})$;

$Z_{e x}$ : the height above ground level $(\mathrm{m})$;

$Z_{10}$ : the reference height $(\mathrm{m})$;

$\alpha$ : the exponent characteristic of terrain roughness.

The exponent $(\alpha)$ can be varied according to the design of the sheltered semi-outdoor spaces in Equation (3a). Variables include the degree of openness or obstruction by trees or walls, as well as the shape and openness of the canopy, all of which can alter the air flow magnitudes and patterns within the sheltered semi-outdoor space.

Hourly wind speed under the canopy was calculated with exponents obtained from the simulation of WinAir4. A different value of exponent $(\alpha)$ can be generated for different types of windbreak or openness for the sheltered semi-outdoor spaces, which will help architects to understand and apply the various design criteria essential to the improvement of outdoor spaces in Table 3.

Table 3. Exponent $(\alpha)$ of the wind speed at different canopy conditions.

\begin{tabular}{ccccc}
\hline \multirow{2}{*}{$\begin{array}{c}\text { Wind } \\
\text { Direction }\end{array}$} & Vzex & Exponent $(\alpha)$ & Vzex & Exponent $(\alpha)$ \\
\cline { 2 - 5 } & 1.12 & 0.80 & 0.51 & 1.14 \\
N & 1.75 & 0.61 & 0.71 & 0.99 \\
NW/NE & 4.02 & 0.24 & 3.35 & 0.32 \\
W & 2.46 & 0.46 & 2.17 & 0.51 \\
SW/SE & 0.80 & 0.94 & 0.54 & 1.11 \\
S & & & \\
\hline
\end{tabular}

$\mathrm{V}_{10}: 7 \mathrm{~m} / \mathrm{s}$, Zex: $1 \mathrm{~m}, \mathrm{Z}_{10}: 10 \mathrm{~m}$; Wind directions (every $\left.45^{\circ}\right): \mathrm{N}\left(337.5^{\circ}-22.5^{\circ}\right), \mathrm{NE}\left(22.5^{\circ}-7.5^{\circ}\right), \mathrm{E}\left(67.5^{\circ}-112.5^{\circ}\right)$,

SE $\left(112.5^{\circ}-157.5^{\circ}\right)$; S $\left(157.5^{\circ}-202.5^{\circ}\right)$, SW $\left(202.5^{\circ}-247.5^{\circ}\right), \mathrm{W}\left(247.5^{\circ}-292.5^{\circ}\right), \mathrm{NW}\left(292.5^{\circ}-337.5^{\circ}\right)$.

Solar radiation and wind speed modified by different canopy conditions were applied as the main variable climate parameters, while temperature and humidity were applied with the original data obtained from Meteonorm 6.0. Rayman v1.2. Software was then applied to simulate the long-term thermal comfort in order to assess conditions in the transitional outdoor space.

Researchers [40,41] have indicated that the mean radiant temperature (Tmrt) has a stronger effect on thermal perception and the values of thermal indices (e.g., PET) than air temperature in an outdoor environment during the summer. That is, solar radiation and the level of shading at various locations play more important roles than air temperature and wind speed when calculating thermal indices. Therefore, although differences exist in atmospheric parameters between specific locations and their nearest weather station, the differences between thermal indices, as calculated by RayMan v1.2 for weather station data and field-measured data, are relatively small and can be discounted [32]. Therefore, this study applied long-term climate data obtained from a weather station for subsequent calculations and analysis. Relative humidity and cloud cover are assumed to be the same as local weather data. 
Simulations were conducted for four types of canopy: no canopy and canopies with transparencies of $0 \%, 50 \%$, and $90 \%$. Once PET comfort levels were calculated, the data was imported into Ecotect and visualised. The graphic displays of these calculations help in understanding the performance of a canopy in accordance with spatial variation. As an extreme case scenario applied in Table 4, the PET levels at noon on $22 \mathrm{July}$, the sunniest day with a clear sky, fall in the range of between $28^{\circ} \mathrm{C}$ ( $0 \%$ transparency canopy) and $47.2{ }^{\circ} \mathrm{C}(90 \%$ transparency canopy). In particular, the area shaded by a $90 \%$ transparency canopy reached $47.2{ }^{\circ} \mathrm{C}$, which is thermally equivalent to very hot, whilst the area shaded by a $0 \%$ transparency canopy remained at $28^{\circ} \mathrm{C}$, thermally equivalent to slightly warm as illustrated in Figure 4.

Table 4. Environmental variables and PET levels with opaque canopy and no canopy on a typical summer and winter day.

\begin{tabular}{cccccccc}
\hline \multirow{2}{*}{ Environmental Variables } & & \multicolumn{3}{c}{ 26 June } & \multicolumn{3}{c}{ 18 December } \\
\cline { 3 - 7 } & & $\mathbf{0 9 : 0 0}$ & $\mathbf{1 2 : 0 0}$ & $\mathbf{1 5 : 0 0}$ & $\mathbf{0 9 : 0 0}$ & $\mathbf{1 2 : 0 0}$ & $\mathbf{1 5 : 0 0}$ \\
\hline Temperature & ${ }^{\circ} \mathrm{C}$ & 16.5 & 20.8 & 22.9 & 9 & 14.9 & 14.2 \\
Humidity & $\%$ & 64 & 49 & 43 & 78 & 54 & 55 \\
Incident solar radiation & $\mathrm{Wh} / \mathrm{m}^{2}$ & 123.2 & 176.6 & 78.6 & 17.9 & 59.9 & 23.7 \\
with an opaque canopy & $\mathrm{Wh} / \mathrm{m}^{2}$ & 418.3 & 618.1 & 367.5 & 38.9 & 83.8 & 57.7 \\
Albedo & 0.3 & & & & & & \\
Cloudiness (clear 0, cloudy 8) & 4 & & & & & & \\
Bowen ratio & & & & & & & \\
\hline
\end{tabular}

1 The Bowen ratio is used to describe the type of heat transfer in a water body. Heat transfer can either occur as sensible heat (differences in temperature without evapotranspiration) or latent heat (the energy required during a change of state, without a change in temperature). Therefore, the surface temperature of the ground can be derived from the air temperature and the wind velocity by taking account of the Bowen ratio.

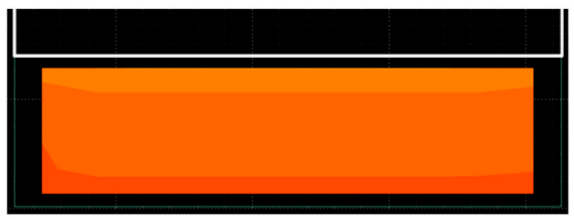

(a) No canopy

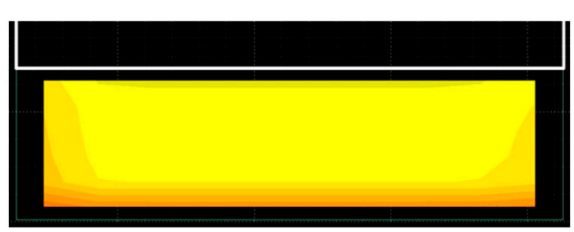

(c) $50 \%$ transparency

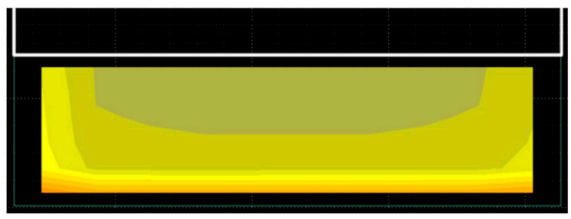

(b) $0 \%$ transparency

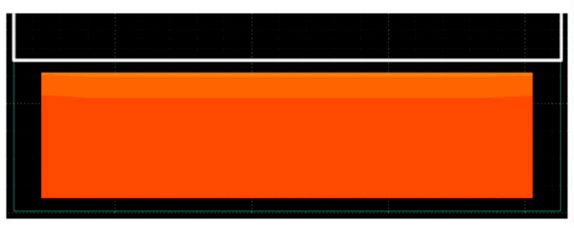

(d) $90 \%$ transparency

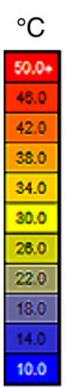

Figure 4. Rendered images of PET comfort levels in the sheltered semi-outdoor spaces at 12:00 on 22 July, the sunniest day, rendered with using Autodesk Ecotect and RayMan v1.2.

PET values change with increased or decreased wind speed on a typical summer or winter day, as seen in Table 5.

Table 5. Environmental variables and PET levels with different wind speeds.

\begin{tabular}{ccccccccc}
\hline \multirow{2}{*}{ PET } & & \multicolumn{3}{c}{ 26 June } & \multicolumn{3}{c}{ 18 December } \\
\cline { 4 - 9 } & & & $\mathbf{0 9 : 0 0}$ & $\mathbf{1 2 : 0 0}$ & $\mathbf{1 5 : 0 0}$ & $\mathbf{0 9 : 0 0}$ & $\mathbf{1 2 : 0 0}$ & $\mathbf{1 5 : 0 0}$ \\
\hline $0 \%$ & Wind $0.25 \mathrm{~m} / \mathrm{s}$ & ${ }^{\circ} \mathrm{C}$ & 18.4 & 25.3 & 22.5 & 5.3 & 13.3 & 10.6 \\
Transparency & Wind $0.5 \mathrm{~m} / \mathrm{s}$ & ${ }^{\circ} \mathrm{C}$ & 17 & 23.8 & 21.6 & 4.5 & 12.3 & 10 \\
$90 \%$ & Wind $0.75 \mathrm{~m} / \mathrm{s}$ & ${ }^{\circ} \mathrm{C}$ & 16.1 & 22.7 & 20.9 & 4.1 & 11.7 & 9.5 \\
\multirow{2}{*}{ Transparency } & Wind $0.25 \mathrm{~m} / \mathrm{s}$ & ${ }^{\circ} \mathrm{C}$ & 33.7 & 47.2 & 37.4 & 6.4 & 14.5 & 12.4 \\
& Wind $0.5 \mathrm{~m} / \mathrm{s}$ & ${ }^{\circ} \mathrm{C}$ & 30.7 & 43.7 & 35.1 & 5.5 & 13.4 & 11.5 \\
& Wind $0.75 \mathrm{~m} / \mathrm{s}$ & ${ }^{\circ} \mathrm{C}$ & 28.5 & 41.2 & 33.4 & 4.9 & 12.7 & 10.9 \\
\hline
\end{tabular}


An opaque canopy blocks incoming solar radiation, which dramatically increases thermal comfort in summer from $90 \%$ transparency to $0 \%$ transparency canopy; $47.2^{\circ} \mathrm{C}$ decreases to $25.3^{\circ} \mathrm{C}$. If the wind increases from $0.25 \mathrm{~m} / \mathrm{s}$ to $0.75 \mathrm{~m} / \mathrm{s}$, the PET falls to $22.7^{\circ} \mathrm{C}$, which makes pupils thermally comfortable. However, the change of PET in winter is small as there is insufficient incident solar radiation to increase pupils' thermal perception. This shows that the PET comfort index is particularly affected by solar radiation as opposed to other environmental parameters. It is useful to examine this for different cities with varied climate conditions, which would have an impact on the outdoor environment.

The frequency of thermal comfort in each month during school hours (09:00-16:00) as shown in Figure 5. Column graphs display thermal comfort ranges in detail, with a nine-colour spectrum used to represent each thermal comfort band in the range of very cold $\left(<4^{\circ} \mathrm{C}\right)$ to very hot $\left(>41^{\circ} \mathrm{C}\right)$. These divided thermal comfort extents can be analysed efficiently for each month. The light green, dark green and yellow coloured areas represent the thermally comfortable frequency; PET values ranging between $13-29^{\circ} \mathrm{C}$ relate to a perceived comfortable temperature of slightly cool to slightly warm. The light green areas represent the neutral temperatures, neither hot nor cold; comfortable temperatures are found between $18-23{ }^{\circ} \mathrm{C}$, which corresponds to $\mathrm{PMV}=0$. Above $29^{\circ} \mathrm{C}$, temperatures are represented by colours of orange to red to show thermally warm, hot and very hot. In contrast, light and dark blue colours represent temperatures that thermally ranged below $13{ }^{\circ} \mathrm{C}$, cool to very cold. From the simulation of conditions in London, use of a $0 \%$ transparency canopy would provide comfort in $93.5 \%$ of daytime hours in July. Also, use of a canopy with $90 \%$ transparency would only provide comfort in $59.4 \%$ of daytime hours and $57.6 \%$ of daytime hours would be comfortable if no canopy were used, as seen in Figure 5.

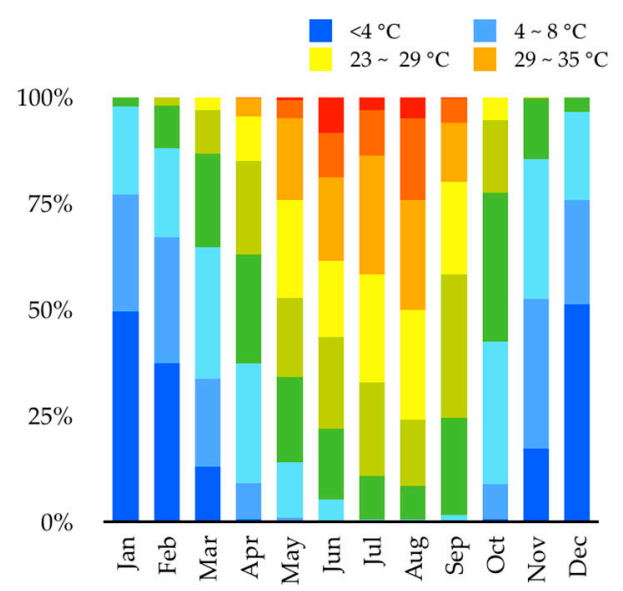

(a) No Canopy

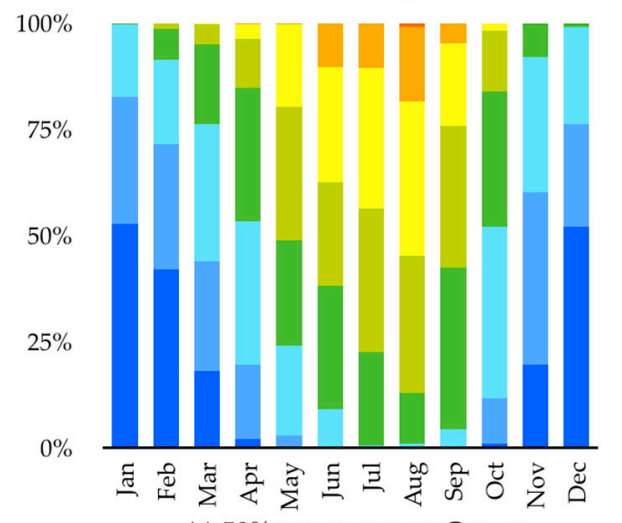

(c) $50 \%$ transparency Canopy

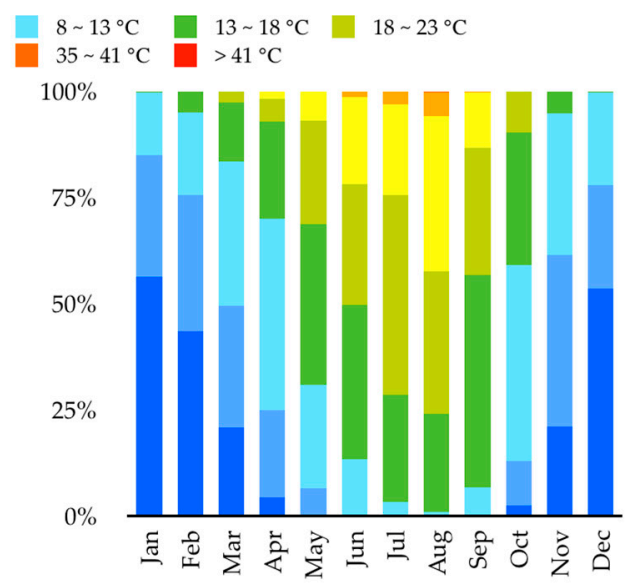

(b) $0 \%$ transparency Canopy

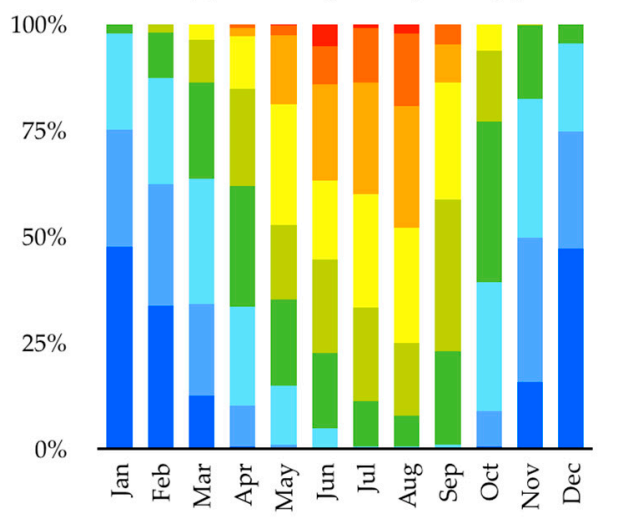

(d) $90 \%$ transparency Canopy

Figure 5. Cumulative frequency of thermal comfort (PET) under the south-facing canopy space during daytime in London. (a) No Canopy (b) 0\% transparency Canopy (c) 50\% transparency Canopy (d) $90 \%$ transparency Canopy. 
Monthly PETs are calculated for a south orientation and shown for each city in Figure 6, (a) for London, (b) for Manchester and (c) for Glasgow. The monthly thermal comfort frequency (Figure 6) shows thermal comfort ranges over the whole year during the daytime (09:00-16:00), revealing that ranges of PET temperature between $13-29^{\circ} \mathrm{C}$ are equivalent to thermal perceptions of slightly cool $\left(13^{\circ} \mathrm{C}\right)$ and slightly warm $\left(29^{\circ} \mathrm{C}\right)$. The simulations that suggest using higher transparencies of the canopy should be considered carefully, mainly because of the thermal discomfort that can arise in summer.

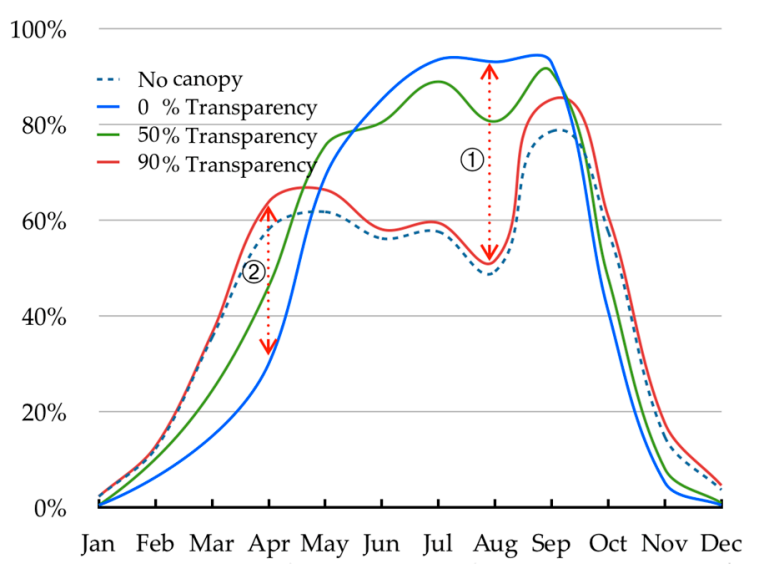

(a)

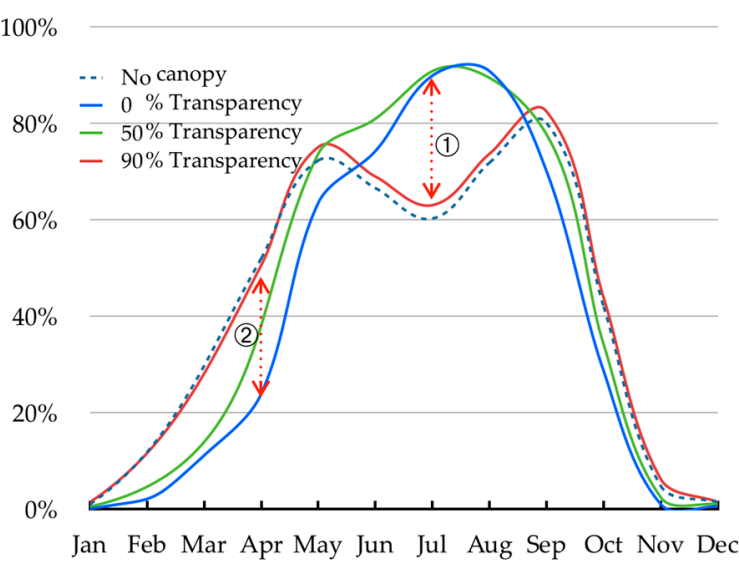

(b)

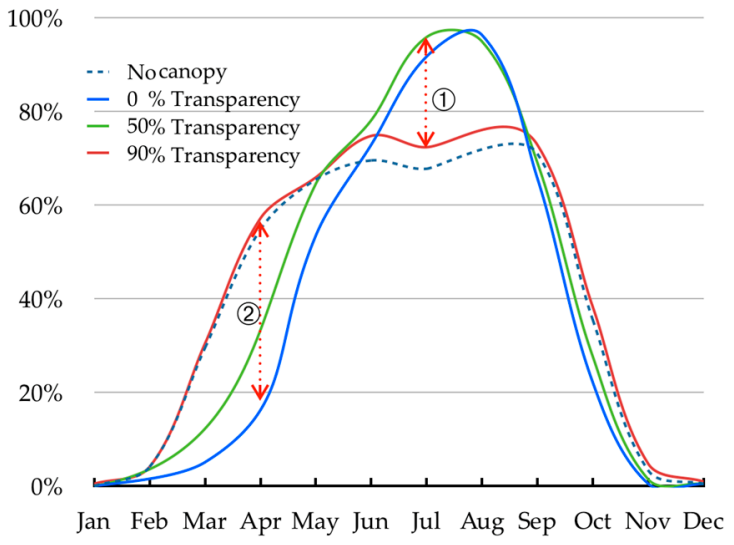

(c)

Figure 6. Frequency of thermally comfortable temperature $\left(13-29^{\circ} \mathrm{CPET}\right)$ during daytime (09:00-16:00). Maximum enhancement of thermal comfort as: (a) 1) 41.5\% in August with $0 \%$ transparency (2) 33.8\% in April with $90 \%$ transparency can be achieved from using $90 \%$ and $0 \%$ transparency canopy respectively in London; (b) (1) $27.7 \%$ in July with $50 \%$ transparency (2) 26.7\% in April with $90 \%$ transparency can be achieved from using $90 \%$ and $0 \%$ transparency canopy respectively in Manchester; (c) 1) $23.5 \%$ in July with 50\% transparency (2) 40.9\% in April with 90\% transparency can be achieved from using $90 \%$ and $0 \%$ transparency canopy respectively in Glasgow.

From the point of view of using the outdoor space, using $50 \%$ transparency canopy can provide the most comfortable outdoor space as 46.3\% hours during daytime (09:00-16:00) were in the comfortable range with this canopy in London. Other transparencies of canopy also show similar performance such as $44.6 \%$ with $0 \%$ transparency and $43.4 \%$ with $90 \%$ transparency of canopy. This clearly showed that seasonal variations in thermal comfort within the transitional outdoor space changed with different canopy transparencies in all the cities. Even though the school summer holidays fall mainly in August, the most problematic period, there can be thermal discomfort between May and July if a canopy with $90 \%$ transparency of canopy is utilised. In winter, a canopy with a higher transparency would lead to a greater number of thermally comfortable hours than one with a lower transparency, though the 
difference would be less than in summer since there is a relative scarcity of solar radiation in the UK during that period.

The sum of thermal comfort frequency in Table 6 in each month shows that in London maximum enhancement of thermal comfort to (1) $41.5 \%$ growth in August can be achieved by using a canopy with $0 \%$ transparency as opposed to a canopy with $90 \%$ transparency, and to (2) 33.8\% increase in April by using a canopy with $90 \%$ transparency as opposed to a canopy of $0 \%$ transparency.

Table 6. Frequency of thermal comfort ranged between $13-29{ }^{\circ} \mathrm{C}$.

\begin{tabular}{cccccc}
\hline & $\mathbf{0} \%$ Transparency & $\mathbf{5 0} \%$ Transparency & $\mathbf{9 0} \%$ Transparency & & \\
\hline \multirow{2}{*}{ London } & $\mathbf{9 3 . 1 \%}$ & $80.6 \%$ & $\mathbf{5 1 . 6 \%}$ & (1) & August \\
& $\mathbf{3 0 . 0} \%$ & $46.2 \%$ & $\mathbf{6 3 . 8} \%$ & (2) & April \\
\hline \multirow{2}{*}{ Manchester } & $89.8 \%$ & $\mathbf{9 0 . 7 \%}$ & $\mathbf{6 3 . 0} \%$ & (1) & July \\
& $\mathbf{2 3 . 8 \%}$ & $33.3 \%$ & $\mathbf{5 0 . 5 \%}$ & (2) & April \\
\hline \multirow{2}{*}{ Glasgow } & $91.7 \%$ & $\mathbf{9 5 . 9 \%}$ & $\mathbf{7 2 . 4 \%}$ & (1) & July \\
& $\mathbf{1 6 . 2 \%}$ & $30.0 \%$ & $\mathbf{5 7 . 1 \%}$ & (2) & April \\
\hline
\end{tabular}

In Manchester, maximum enhancement of thermal comfort to (1) $27.7 \%$ improvement in July can be achieved by using a canopy of $50 \%$ transparency rather than of $90 \%$ transparency and (2) $26.7 \%$ enhancement in April by using a canopy of $90 \%$ transparency rather than of $0 \%$ transparency canopy, while in Glasgow maximum enhancement of thermal comfort to (1) $23.5 \%$ in July can be achieved with a canopy of 50\% transparency rather than $90 \%$ transparency and to (2) $40.9 \%$ increase in April with a canopy of $90 \%$ transparency rather than one of $0 \%$ transparency.

Findings are summarised as follows.

- It is difficult to achieve outdoor thermal comfort during school hours in January, February, November and December in all of the cities studied;

- Though it is not possible to provide temperatures that reach the thermal comfort temperature threshold from January to February by using a canopy of any transparency, use of a canopy of $90 \%$ transparency will produce PET values of around $3.5^{\circ} \mathrm{C}$ higher than those achieved using an opaque canopy at noon in February in London;

- In April, use of a canopy of $90 \%$ transparency allows thermal comfort to be achieved during most of the school day. However, canopies of other transparencies lead to a value mostly below $13{ }^{\circ} \mathrm{C}$, the minimum thermally comfortable temperature;

- During the summer term from late April through to the middle of July, outdoor thermal comfort can be achieved during the school day with most canopies, with the exception of the canopy of $90 \%$ transparency at around noon in June and July;

- A canopy of $50 \%$ transparency showed the best performance across a range of thermal comfort values between $18-23^{\circ} \mathrm{C}$ during the summer term;

- School summer holidays are normally 6 weeks from the middle of July until the end of August, thus allowing the school to avoid the highest amount of solar radiation of the year. However, if school premises are used for extended education for the general community during this period, use of an opaque canopy is preferable to keep solar radiation from reaching the ground;

- Outdoor thermal comfort levels drop quickly in October but the use of a canopy of $90 \%$ transparency will allow temperatures above $13{ }^{\circ} \mathrm{C}$ to be maintained over most of the school day;

- The period from December to February is the most difficult period in which to keep the temperature of an outdoor space high enough, as thermal temperatures range between only $2.8-7.6^{\circ} \mathrm{C}$ at noon each month, giving a thermal perception of "very cold" to "cold".

If it is not possible to vary the transparency of the canopy used, teachers can achieve better outdoor comfort by changing the time patterns of use of the outdoor spaces. For instance, in the summer term, they could encourage pupils to use the space in the early morning or late afternoon 
instead of using it as an outdoor classroom in the middle of the day. Conversely, during the spring and winter terms, the outdoor classroom might be most comfortable at around noon when solar radiation is at its peak.

Outdoor thermal comfort simulations are extended to different orientations and other cities using typical climate data for each area. Figure 7 has been generated to show annual thermal comfort in the transitional outdoor space for each of four installation orientations (east, south, west and north) for three main cities; London, Manchester, Glasgow. It provides an overview of how much thermal comfort falls annually within the range of between $13-29^{\circ} \mathrm{C}$, using the PET index for outdoor thermal comfort.

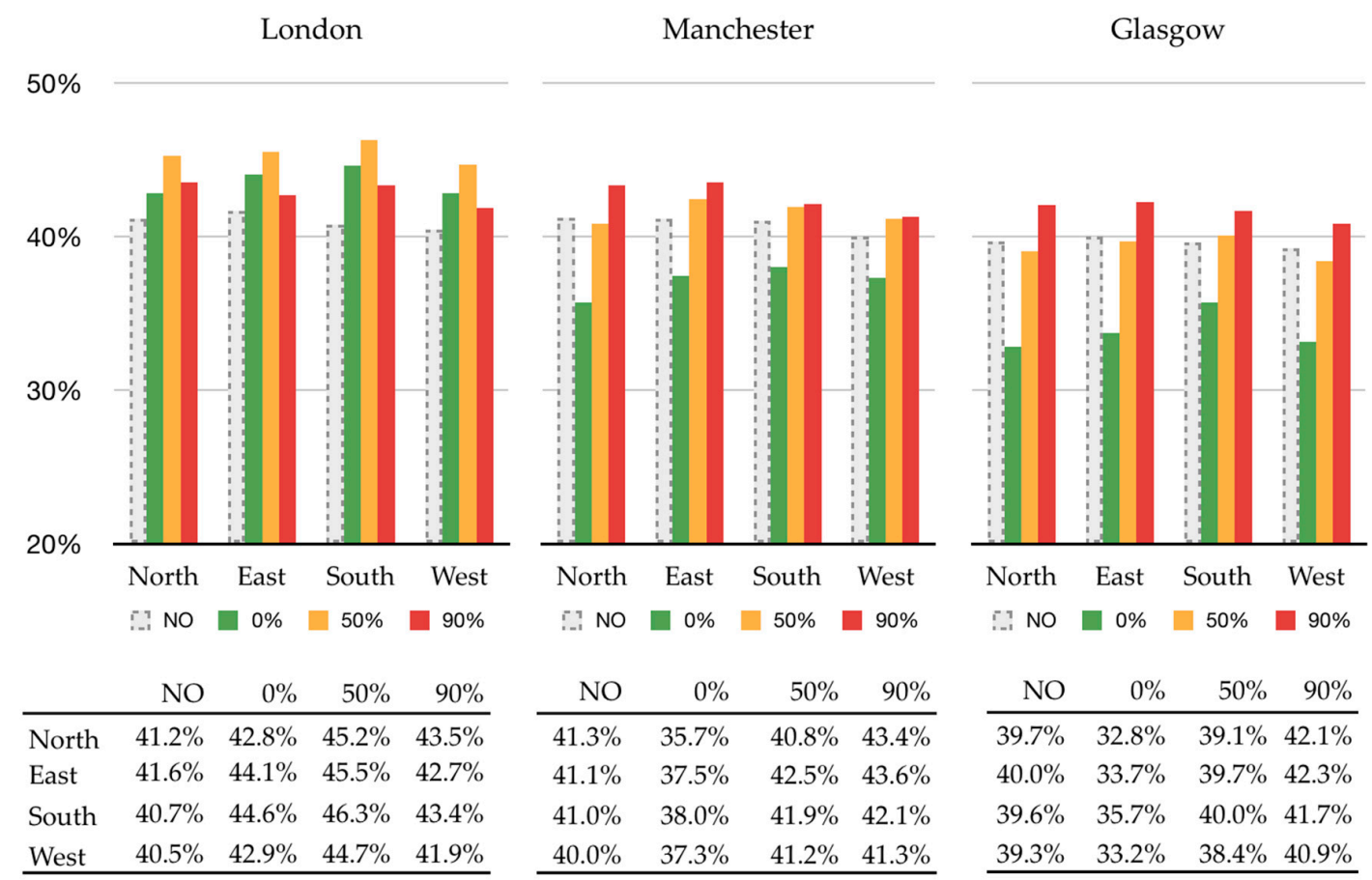

Figure 7. Annual frequency of thermal comfort ranged $13-29{ }^{\circ} \mathrm{C}$ in the sheltered outdoor space in London, Manchester and Glasgow.

- When no canopy is provided, there is little difference between orientations for outdoor thermal comfort, whilst once a canopy is applied, thermal comfort achievement varies greatly depending on orientations and transparency;

- Thermal comfort using $0 \%$ transparency canopy (green bar) becomes lower in higher latitudes, mainly due to reduced solar radiation;

- Performance of a $0 \%$ transparency (green bar) canopy facing south in London is particularly noticeable; improving thermal comfort by $6.6 \%$ and $8.9 \%$ compared with Manchester and Glasgow respectively;

- A 50\% transparency canopy (orange bar) shows mostly good results for all orientations in all three cities. Only a $0 \%$ transparency canopy oriented south or east in London represents slightly better performance, because incident solar radiation is higher than when oriented to north or west;

- The higher the latitude of the city, the higher the transparency of canopy is needed in order to maximise outdoor thermal comfort;

- Installation of a canopy with any transparency is shown to provide better overall outdoor comfort than can be achieved without a canopy for all orientations, with the exception of a $0 \%$ transparency canopy in Manchester and Glasgow. Those cases show worse performance when using an opaque canopy because of the lack of solar radiation reduced by high latitudes.

- More specific findings for each of the cities are as follows: 
London

- Where no canopy is provided, orientation to north or east can provide slightly better outdoor comfort than orientation to the south or west as south and west orientations are subject to relatively high amounts of solar radiation;

- The simulation shows that a 50\% transparency canopy provides the best performance in all directions. Overall, canopies with transparencies of $50 \%$ or less should be recommended for use in London. Using a canopy of $90 \%$ transparency provides little improvement (in the range of 2.4-2.9\%) regardless of orientation compared with no provision of a canopy, according to the simulation;

- For south-facing outdoor spaces, the provision of a canopy of 50\% transparency in particular shows around $6 \%$ improvement in outdoor comfort compared with situations where no canopy is provided; $6 \%$ is equivalent to around $83.7 \mathrm{~h}$ (12 days) during school terms.

Manchester

- A $90 \%$ transparency canopy displays the best performance for all orientations of the outdoor space. When space faces north, using a 90\% transparency canopy provides more than $4.1 \%(59.4 \mathrm{~h})$ improvement in the provision of outdoor comfort than in the case where a $0 \%$ transparency canopy is provided;

- A $0 \%$ transparency canopy also shows comparatively poor thermal comfort performance for transitional spaces in all directions, even worse than without a canopy. When the outdoor space faces north using an opaque canopy, thermal comfort performance is poor, which indicates that opaque and low transparency canopies should be avoided in higher latitudes;

- A $90 \%$ transparency of canopy provides the best improvement (a range of $4.0-7.7 \%$, equivalent to $58-112 \mathrm{~h}$ ) in comparison to a situation where $0 \%$ transparency canopy is provided;

- Canopies of 90\% transparency can be used to prolong outdoor comfort for outdoor spaces facing north or east, while both $50 \%$ and $90 \%$ transparency canopies are appropriate for spaces with orientations to south or west;

Glasgow

- Overall, outdoor comfort levels are slightly lower than in other cities as there is a relatively long winter period, during which outdoor thermal comfort is difficult to achieve;

- A canopy of $90 \%$ transparency is the most appropriate choice regardless of the orientation of the outdoor space, providing an improvement in thermally comfortable occupancy in the range of $40.9-42.3 \%$ (593-613 h).

- Transitional outdoor spaces oriented north and east also show good performances of around $42 \%$ thermal comfort frequency with $90 \%$ transparency canopy. In general, high transparencies (above $50 \%$ ) of canopy show better results than low transparencies in all directions.

\section{Conclusions}

This research was conducted in the context of school buildings in the UK where the interest in outdoor education is growing, and architectural spaces are increasingly being created and used outdoors. Among various architectural elements of the sheltered transitional space that have an impact on environmental performance, the canopy has been chosen for exploration as it is the main architectural device that has frequently been used in schools in the UK.

The environmental quality of a sheltered transitional space was estimated through a thermal comfort index, PET (Physiological Equivalent Temperature), which is one of the popular indices for outdoor spaces. Several computer software packages (e.g., Ecotect, RayMan, etc.) were used for the environmental analysis, and meteorological data from Meteonorm 6.0 was used for the 
computer simulations. With the help of specifically developed software and hardware, large amounts of complicated data can be calculated to estimate the environmental performance of a particular space under varying parameters. The outdoor thermal comfort was explored using canopies of differing transparencies. Solar radiation and wind speed in the sheltered semi-outdoor space were calculated using Autodesk Ecotect and WinAir4. Once obtained, the hourly data was input into RayMan v1.2 for calculation of the thermal comfort index, PET. This study showed the environmental potential of the sheltered semi-outdoor space through changing the transparency of the canopy. This study can help architects and engineers design environmentally sophisticated external spaces within schools by proposing guidelines for the design of sheltered transitional spaces, which could compensate for the possible environmental drawbacks from the instalment of the architectural elements of the sheltered transitional space.

The results are summarised as follows:

- The ratios of incident solar radiation increase rapidly in summer as does with the direct solar radiation, which implies that solar control in summer is crucial to enhance thermal comfort. Due to the relative shortage of solar radiation in winter, control of wind speed as another environmental factor is a key design concern;

- Reduced wind speed, in combination with solar radiation, helps to increase thermal comfort in winter, whilst it leads to deterioration in outdoor thermal conditions in summer;

- Thermal comfort in a sheltered semi-outdoor space can be varied by using different transparencies and orientations of the canopy. Thus, choosing an appropriate canopy transparency combined with orientation is critical in order to enable it to be used as an extended classroom for much of the year;

- From the simulation, it is hard to achieve outdoor thermal comfort from November to February, where outdoor thermal comfort can be no more than $10 \%$ during the daytime in all cities;

- Use of an opaque or low (less than 50\%) transparency canopy is advisable to keep outdoor thermal comfort within the comfortable thermal band of between $13-29^{\circ} \mathrm{C}$ in summer in all cities;

- Exposure to as much solar radiation as possible using a higher transparency canopy is preferable during the winter and spring terms;

- The overall percentage of thermal comfort is reduced when applied to school terms only, rather than using the time scale of the whole year. The reduction is mainly attributable to the school holidays, a total of about 13 weeks, of which six weeks are in summer months when occurrence of a thermal problem is frequent. During the summer period, low transparencies of canopy perform better than $90 \%$ transparency canopies by providing protection from direct solar radiation. However, as there are schools that may open all year round for provision of adult or nursery education, care must be taken when applying school terms for the simulation;

- Thus, it is necessary for architects to find out the expected seasonal use of the space, i.e., either school terms only or throughout the year, before designing a transitional outdoor space.

Acknowledgments: This work was supported by the Infrastructure and Transportation Technology Promotion Research Programme of the Ministry of Land, Infrastructure and Transport of South Korea grant no. 15CTAP-C097447-01.

Author Contributions: Authors equally contributed to the paper.

Conflicts of Interest: The author declares no conflict of interest.

\section{References}

1. DfES. Schools for the Future: Designing School Grounds; TSO (The Stationery Office): London, UK, 2006 ; p. 117.

2. DfES. The Outdoor Classroom: Educational Use, Landscape Design and Management of School Grounds, 2nd ed.; DfES: Perth, Australia, 1999.

3. Acar, H. Learning environments for children in outdoor spaces. Procedia Soc. Behav. Sci. 2014, 141, $846-853$. [CrossRef] 
4. Kweon, B.-S.; Ellis, C.D.; Lee, J.; Jacobs, K. The link between school environments and student academic performance. Urban For. Urban Green. 2017, 23, 35-43. [CrossRef]

5. Gelfand, L.; Freed, E.C. Sustainable School Architecture: Design for Primary and Secondary Schools; John Wiley [distributor]: Hoboken, NJ, USA; Chichester, UK, 2010.

6. DfES. Schools for the Future: Exemplar Designs, Concepts and Ideas; Department for Education and Skills: London, UK, 2004; p. 120.

7. Taylor, A.P.; Enggass, K. Linking Architecture and Education: Sustainable Design for Learning Environments; University of New Mexico Press: London, UK; Eurospan [distributor]: Albuquerque, NM, USA, 2009.

8. Givoni, B. Climate Considerations in Building and Urban Design; Van Nostrand Reinhold: New York, NY, USA; London, UK, 1998; p. 464.

9. Santamouris, M. Energy and Climate in the Urban Built Environment; James \& James: London, UK, 2001; 402p.

10. Pitts, A.; Bin Saleh, J. Potential for energy saving in building transition spaces. Energy Build. 2007, 39, 815-822. [CrossRef]

11. Nikolopoulou, M. Designing Open Spaces in the Urban Environment: A Bioclimatic Approach (Ruros); Centre for Renewable Energy Sources (C.R.E.S.): Pikermi, Greece, 2004.

12. Johansson, E. Influence of urban geometry on outdoor thermal comfort in a hot dry climate: A study in fez, morocco. Build. Environ. 2006, 41, 1326-1338. [CrossRef]

13. Oke, T.R. Boundary Layer Climates, 2nd ed.; Methuen: London, UK, 1987; p. 416.

14. Huang, J.; Zhou, C.; Zhuo, Y.; Xu, L.; Jiang, Y. Outdoor thermal environments and activities in open space: An experiment study in humid subtropical climates. Build. Environ. 2016, 103, 238-249. [CrossRef]

15. Fanger, P.O. Thermal Comfort; McGraw Hill: New York, NY, USA, 1972.

16. Hoppe, P. Different aspects of assessing indoor and outdoor thermal comfort. Energy Build. 2002, 34, 661-665. [CrossRef]

17. Aljawabra, F.A. Thermal Comfort in Outdoor Urban Spaces: The Hot Arid Climate. Ph.D. Thesis, University of Bath, Bath, UK, 2014.

18. Taleghani, M.; Kleerekoper, L.; Tenpierik, M.; van den Dobbelsteen, A. Outdoor thermal comfort within five different urban forms in The Netherlands. Build. Environ. 2015, 83, 65-78. [CrossRef]

19. Steemers, K.; Steane, M.A. Environmental Diversity in Architecture; Spon Press: London, UK, 2004; p. 237.

20. Hawkes, D. The Environmental Tradition: Studies in the Architecture of Environment; E. \& F.N. Spon: London, UK, 1996; p. 212.

21. Van Esch, M.M.E.; Looman, R.H.J.; de Bruin-Hordijk, G.J. The effects of urban and building design parameters on solar access to the urban canyon and the potential for direct passive solar heating strategies. Energy Build. 2012, 47, 189-200. [CrossRef]

22. Baker, N.; Steemers, K. Energy and Environment in Architecture: A Technical Design Guide; E. \& FN. Spon: New York, NY, USA, 1999.

23. Lu, S.; Xia, H.; Wei, S.; Fang, K.; Qi, Y. Analysis of the differences in thermal comfort between locals and tourists and genders in semi-open spaces under natural ventilation on a tropical island. Energy Build. 2016, 129, 264-273. [CrossRef]

24. Hosseini, S.H.; Shokry, E.; Ahmadian Hosseini, A.J.; Ahmadi, G.; Calautit, J.K. Evaluation of airflow and thermal comfort in buildings ventilated with wind catchers: Simulation of conditions in Yazd City, Iran. Energy Sustain. Dev. 2016, 35, 7-24. [CrossRef]

25. Oreszczyn, T. The Efficient Collection and long Term Storage of solar Energy in the UK, Using Air as the Working Fluid. Available online: http:/ / ethos.bl.uk/OrderDetails.do?uin=uk.bl.ethos.332631 (accessed on 22 September 2017).

26. Szokolay, S.V.; Auliciems, A. PLEA Notes 3: Thermal Comfort PLEA: Passive and Low Energy Architecture International; University of Queensland: Brisbane, Australia, 1997 (revised 2007).

27. CIBSE. Comfort; CIBSE: London, UK, 2006.

28. He, Y.; Jones, P.J.; Rayment, M. A simple parameterisation of windbreak effects on wind speed reduction and resulting thermal benefits to sheep. Agric. For. Meteorol. 2017, 239, 96-107. [CrossRef]

29. Lau, K.K.-L.; Ren, C.; Ho, J.; Ng, E. Numerical modelling of mean radiant temperature in high-density sub-tropical urban environment. Energy Build. 2016, 114, 80-86. [CrossRef]

30. Xue, S.; Xiao, Y. Study on the outdoor thermal comfort threshold of lingnan garden in summer. Procedia Eng. 2016, 169, 422-430. [CrossRef] 
31. Szokolay, S.V. Introduction to Architectural Science: The Basis of Sustainable Design, 2nd ed.; Elsevier Architectural Press: Amsterdam, The Netherlands; London, UK, 2008; p. 345.

32. Matzarakis, A.; Mayer, H.; Iziomon, M.G. Applications of a universal thermal index: Physiological equivalent temperature. Int. J. Biometeorol. 1999, 43, 76-84. [CrossRef] [PubMed]

33. Kang, K.-N.; Song, D.; Schiavon, S. Correlations in thermal comfort and natural wind. J. Therm. Biol. 2013, 38, 419-426. [CrossRef]

34. Tan, C.L.; Wong, N.H.; Jusuf, S.K. Effects of vertical greenery on mean radiant temperature in the tropical urban environment. Landsc. Urban Plan. 2014, 127, 52-64. [CrossRef]

35. Ketterer, C.; Matzarakis, A. Human-biometeorological assessment of heat stress reduction by replanning measures in Stuttgart, Germany. Landsc. Urban Plan. 2014, 122, 78-88. [CrossRef]

36. Littlefield, D. Metric Handbook: Planning and Design Data, 3rd ed.; Architectural Press: London, UK, 2008; p. $1 \mathrm{v}$.

37. Great Britain. Department for, Education; Skills. In Building Bulletin 99: Building Framework for Primary School Projects; TSO: Norwich, UK, 2003.

38. Autodesk Ecotect Analysis. Available online: https://www.autodesk.com/education/free-software/ecotectanalysis (accessed on 1 March 2017).

39. Dear, R.D.; Spagnolo, J.; Yutaka, T.; Tadakatsu, O. Thermal comfort in outdoor and semi-outdoor environments. In Elsevier Ergonomics Book Series; Elsevier: Amsterdam, The Netherlands, 2005; Volume 3, pp. 269-276.

40. Coccolo, S.; Kämpf, J.; Scartezzini, J.-L.; Pearlmutter, D. Outdoor human comfort and thermal stress: A comprehensive review on models and standards. Urban Clim. 2016, 18, 33-57. [CrossRef]

41. Matzarakis, A.; Rutz, F.; Mayer, H. Modelling radiation fluxes in simple and complex environments-Application of the rayman model. Int. J. Biometeorol. 2006, 51, 323-334. [CrossRef] [PubMed]

(C) 2017 by the authors. Licensee MDPI, Basel, Switzerland. This article is an open access article distributed under the terms and conditions of the Creative Commons Attribution (CC BY) license (http://creativecommons.org/licenses/by/4.0/). 